Research Journal of Applied Sciences 5 (1): 1-6, 2010

ISSN: $1815-932 \mathrm{X}$

(C) Medwell Journals, 2010

\title{
Mathematical Modeling and Numerical Simulation of Glucose-Insulin System for Diabetic Therapeutic Management
}

\author{
${ }^{1}$ Babagana Gutti, ${ }^{2}$ Alfred A. Susu and ${ }^{3}$ Olufemi A. Fasanmade \\ ${ }^{1}$ Department of Chemical Engineering, University of Maiduguri, Maiduguri, Borno, Nigeria \\ ${ }^{2}$ Department of Chemical Engineering, University of Lagos, Lagos, Nigeria \\ ${ }^{3}$ College of Medicine, University of Lagos, Lagos, Nigeria
}

\begin{abstract}
The pathogenesis of diabetes is still not understood and various potential causes are usually investigated through complex in vitro or in vivo experimentation. A mathematical model able to describe insulin-glucose kinetics during simple clinical tests such as insulin and glucose tolerance test was developed. This model can quantify in individual patients, macroscopic physiological process that may be associated with the development of diabetic disease and the model was validated with numerically significant group of subjects. Eighty seven subjects participated in the study. The gut-blood system was modeled as an infinite number of continuous stirred tanks in series. The model was solved using Laplace transformation. The model quantifies the amount of insulin needed for the administration of individuals at different times to keep the glucose level in check. Statistical analysis shows that there was no statistical difference $(p<0.05)$ between the measured and simulated mean plasma insulin levels and the corresponding plasma glucose levels.
\end{abstract}

Key words: Glucose, insulin, blood, gut, diabetes, mathematical model

\section{INTRODUCTION}

Diabetes is related with imbalance of glucose in the human system. A correct glucose metabolism is one of the key factors in keeping a healthy state in mammals. Among other processes, this is accomplished mostly via regulatory action of hormones released by specific cell population inside the pancreas. A very relevant role is played in this process by the hormone, insulin, synthesized by the pancreatic cells. The normal blood glucose concentration level in humans is in a narrow range (70-110 $\mathrm{mg} \mathrm{dL}^{-1}$ ) (Makroglou et al., 2006). Exogenous factors that affect the blood glucose concentration level include food in-take, rate of digestion, exercise, reproductive state, etc. The pancreatic endocrine hormones, insulin and glucagons are responsible for keeping the glucose concentration level in check. Several attempts at building a satisfactory model of the glucose-insulin system are recorded in the literature. The minimal model (Bergman and Cobelli, 1980), which is the model currently and mostly used in physiological research on the metabolism of glucose was proposed in the early eighties for the interpretation of the glucose and insulin plasma concentrations following the Intra-Venous Glucose Tolerance Test (IVGTT) (Shen et al., 1970). Himsworth (1936) identified two different types of diabetes mellitus: the insulin-sensitive and the insulininsensitive types, by using an insulin-glucose test. Since then, several other methods have been used to quantify insulin action. The tests that have been used to assess insulin sensitivity include: insulinogenic ratio (insulin/glucose) (Gaetano and Arino, 2000), glucose/insulin ratio (Seltzer et al., 1967), glucose clamp technique (De Fronzo et al., 1979), Frequently Sampled Intravenous Glucose Tolerance test (FSIGT) (Kahn et al., 1993) and minimal model technique (Bergman et al., 1987). Another simple and reliable test, the Short Insulin Tolerance Test (SITT) was developed by Bonora et al. (1989). There has been no model study, as far as the researchers are aware, on glucose disappearance from blood plasma in Nigerians. However, a glucose disappearance study on Nigerians was carried out by Fasanmade (1987) using the short insulin tolerance test. No models were developed in that study and glucose disappearance rate constants were determined using the least square method on patient data.

Although, insulin plays a role in carbohydrate, proteins and fats metabolism, this study has been narrowed down to the modeling of glucose (carbohydrate) metabolism, following the short insulin tolerance test (Bonora et al., 1989). Diabetes mellitus is a disease of the glucose-insulin regulatory system (Bergman et al., 2002;

Corresponding Author: Babagana Gutti, Department of Chemical Engineering, University of Maiduguri, Maiduguri, Borno State, Nigeria 
Topp et al., 2000), which is referred to as hyperglycemia. Diabetes is classified into two main categories: Type 1 diabetes, juvenile onset and insulin-dependent and Type 2 diabetes, adult onset and insulin-independent. Type 1 diabetes is caused by deficiency of circulating insulin due to the loss of insulin producing $\beta$-cells in the Langerhans islets of the pancreas (Makroglou et al., 2006), while Type 2 diabetes is caused by the failure of pancreatic beta cells to respond appropriately to the prevailing blood glucose levels (Bakari and Onyemelukwe, 2005). To this day, the standard treatment for Type 1 diabetes mellitus is the administration of exogenous insulin to mimic the normal metabolic regulatory system in healthy subjects. Insulin facilitates cellular glucose uptake and stimulates conversion of glucose into glycogen (Gerich, 1993).

Mathematical formulation: The gut-blood system was modeled as an infinite number of continuous stirred tanks in series, which could be used as simulators of the entire blood glucose-insulin system. If a certain amount of Glucose $\mathrm{N}_{0}$ is suddenly injected in one shot into the blood stream and assuming the blood stream can be represented by infinite number of equal volume mixed flow reactors, arrange in series as shown in Fig. 1. The outlet concentration $C_{n}$ is then measured. If we first choose an increment of time $\Delta \mathrm{t}$ sufficiently small that the concentration of glucose, $C(t)$, exiting between time $t$ and $\mathrm{t}+\Delta \mathrm{t}$ is essentially constant. The amount of glucose, $\Delta \mathrm{N}$ leaving the reactor between $t$ and $t+\Delta t$ is then:

$$
\Delta \mathrm{N}=\mathrm{C}(\mathrm{t}) \mathrm{F} \Delta \mathrm{t}
$$

Where:

$\mathrm{F}=$ The effluent volumetric flow rate in other words

$\Delta \mathrm{N}=$ The amount of glucose that has spent an amount of time between $\mathrm{t}$ and $\mathrm{t}+\Delta \mathrm{t}$ in the reactor

A material balance on the glucose in the second reactor gives the following Eq. 2:

$$
\frac{\mathrm{dC}_{2}}{\mathrm{dt}}+\frac{\mathrm{C}_{2}}{\tau_{\mathrm{i}}}=\frac{\mathrm{C}_{0}}{\tau_{\mathrm{i}}} \mathrm{e}^{\frac{\mathrm{t}}{\tau_{\mathrm{i}}}}
$$

Model solution and simulation of the glucose and insulin kinetics: Using Laplace transformation to Eq. 2, the analytical solution of the model is as follows:

$$
\mathrm{C}_{2}=\frac{\mathrm{C}_{0}}{\tau_{\mathrm{i}}} \mathrm{te}^{-\frac{\mathrm{t}}{\tau_{\mathrm{i}}}}
$$

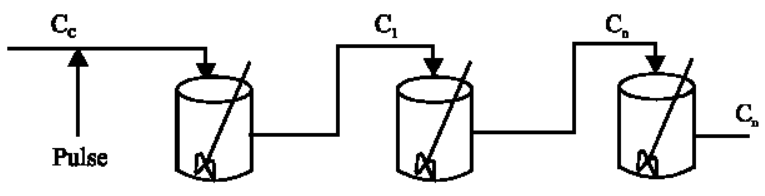

Fig. 1: Gut and blood compartment represented as tanks in series

The same procedure used for the third reactor gives the expression for the concentration of tracer in the effluent from the third reactor and therefore from the reactor system:

$$
\mathrm{C}_{3}=\frac{\mathrm{C}_{0}}{\tau_{\mathrm{i}}^{2}} \mathrm{t}^{2} \mathrm{e}^{-\frac{\mathrm{t}}{\tau_{\mathrm{i}}}}
$$

The volumetric flow rate $\mathrm{F}$ is usually constant, so we can define $\mathrm{E}(\mathrm{t})$ as:

$$
E(t)=\frac{C_{3}(t)}{\int_{0}^{\infty} C_{3}(t) d t}
$$

Substituting Eq. 3 in Eq. 5 gives:

$$
E(t)=\frac{C_{3}(t)}{\int_{0}^{\infty} C_{3}(t) d t}=\frac{t^{2}}{2 t^{3}} e^{-\frac{t}{5}}
$$

Generalizing this method to a series of $\mathrm{n}$ CSTRs gives the RTD for $\mathrm{n}$ CSTRs in series, $\mathrm{E}(\mathrm{t})$ :

$$
E(t)=\frac{t^{n-1}}{(n-1) ! \tau_{1}^{n}} e^{-\frac{t}{\tau}}
$$

Because the total reactor volumes is $n V_{i}$, then $\tau_{i}=\tau / n$, where, $\tau$ represent the total reactor volume divided by the flow rate, $\mathrm{F}$ :

$$
E(\Theta)=\frac{n(n \Theta)^{n-1}}{(n-1) !} e^{-n \Theta}
$$

where, $\Theta=t / \tau$.

We can determine the number of tanks in series by calculating the dimensionless variance $\delta_{\oplus}^{2}$ from:

$$
\begin{gathered}
\sigma_{\Theta}^{2}=\frac{\mathrm{n}^{\mathrm{n}}}{(\mathrm{n}-1) !} \int_{0}^{\infty} \Theta^{\mathrm{n}+1} \mathrm{e}^{-\mathrm{n} \Theta} \mathrm{d}(\Theta)-1 \\
\frac{\mathrm{n}^{\mathrm{n}}}{(\mathrm{n}-1)}\left[\frac{(\mathrm{n}+1) !}{\mathrm{n}^{\mathrm{n}+2}}\right]-1
\end{gathered}
$$


The number of tanks in series is:

$$
\mathrm{n}=\frac{1}{\sigma_{\Theta}^{2}}=\frac{\tau^{2}}{\sigma_{\Theta}^{2}}
$$

This expression represents the number of tanks necessary to model the real reactor as $\mathrm{n}$ ideal tanks in series.

Since the reaction is first order; the effluent concentration from the reactor in generalized form for $n$th reactor is:

$$
\mathrm{C}^{\mathrm{n}}=\frac{\mathrm{C}_{0}}{(1+\tau \mathrm{k})^{\mathrm{n}}}
$$

The conversion for these tanks in series would be

$$
\mathrm{X}=1-\frac{1}{(1+\tau \mathrm{k})^{\mathrm{n}}}
$$

Where:

$$
\tau_{\mathrm{i}}=\frac{\mathrm{V}}{\mathrm{Fn}}
$$

\section{RESULTS AND DISCUSSION}

For the evaluation and analysis, two groups of adult Nigerians were studied; patients with Non Insulin Dependent Diabetes Mellitus (NIDDM) within the age range of 25-60 years and healthy volunteers without hypertension, glucose intolerance who were in a similar age range $25-60$ years. The persons with diabetes were selected from the diabetes out-patient and the general out-patient clinics of the Lagos University Teaching Hospital, Lagos, Nigeria. All consecutive consenting patients who satisfied study criteria were recruited. The control group was drawn from similar socio-economic group as the study group and they were age and sex matched for age and sex as closely as possible. Exclusion criteria for the study group and control are:

Control group: Exclusion criteria included previous history of glucose intolerance, past or present history of smoking, use of drugs or agents known to alter glucose tolerance or insulin sensitivity, history of seizures, angina, myocardial infarction, hypertension or stroke.

Study group: Exclusion criteria included current or recent use of insulin to control diabetes, presence of acute metabolic or other disabling medical or surgical conditions including foot uncer (s). Other exclusion criteria included history of smoking, seizures, angina, myocardial infarction, hypertension, heart failure or smoke.
A total of 87 volunteers who met the inclusion criteria participated in the study. This was made up of $37(42.53 \%)$ females and $50(57.47 \%)$ males. Twenty six $(52 \%)$, out of the 50 males were diabetic, while the remaining 24 served as control male subjects. Seventeen (45.95\%) out of the 37 females were diabetic, while the remaining 20 served as control female subjects. Out of the 44 male and female control $29(65.90 \%)$ of them are $<35$ years, while the ages of the remaining 15 is $>35$ years. Thirty seven $(86 \%)$ out of the 44 diabetic male and female are above the age of 35 years, while the remaining $6(14 \%)$ are $<35$ years of age. Figure 2 shows the measured and simulated glucose profile.

The measured profile started at a fasting concentration of $71.10 \mathrm{mg} \mathrm{dL}^{-1}$ and reached the maximum concentration of $135.90 \mathrm{mg} \mathrm{dL}^{-1}$ at $30 \mathrm{~min}$ after consumption of glucose before it gradually reduced to $91.53 \mathrm{mg} \mathrm{dL}^{-1}$ at $120 \mathrm{~min}$ but the simulated profile started at a maximum concentration of $140 \mathrm{mg} \mathrm{dL}^{-1}$ at $0 \mathrm{~min}$ and gradually reduced with time to minimum concentration of $73.31 \mathrm{mg} \mathrm{dL}^{-1}$ at $120 \mathrm{~min}$. This shows that $4.10 \mathrm{mg} \mathrm{dL}^{-1}$ of glucose was dissipated between 0 and $30 \mathrm{~min}$ before the maximum concentration was reached. Figure 3 show the simulated and measured insulin profile. The measured profile started at a fasting concentration of $5.72 \mu \mathrm{U} \mathrm{mL}^{-1}$ and reached the maximum concentration of $15.58 \mu \mathrm{U} \mathrm{mL}^{-1}$

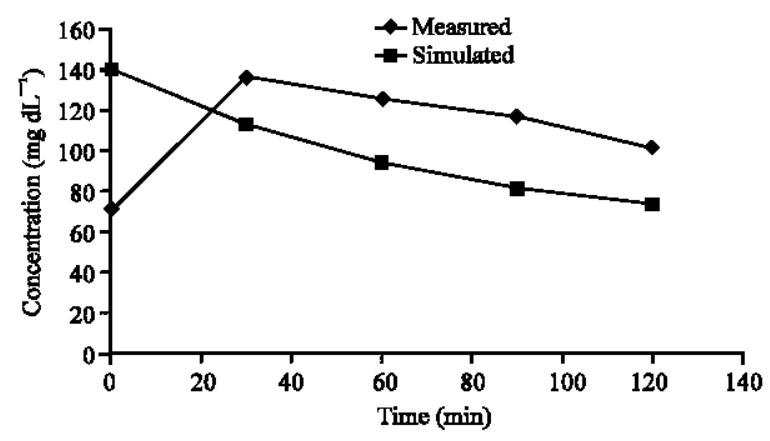

Fig. 2: Measured and simulated glucose profile

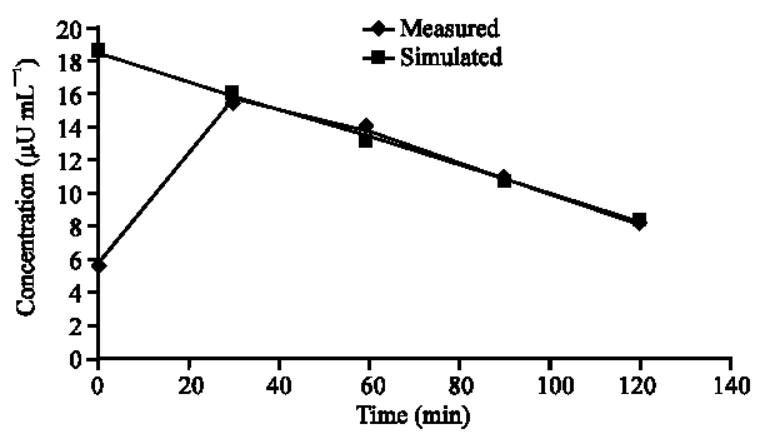

Fig. 3: Measured and simulated plasma insulin profile 
at 30 min after consumption of glucose before it gradually reduced to $8.03 \mu \mathrm{U} \mathrm{mL}^{-1}$ at $120 \mathrm{~min}$ but the simulated profile started at a maximum concentration of $18.40 \mu \mathrm{U} \mathrm{mL}^{-1}$ at $0 \mathrm{~min}$ and gradually reduced with time to minimum concentration of $8.20 \mu \mathrm{U} \mathrm{mL}^{-1}$ at $120 \mathrm{~min}$. This shows that $2.82 \mu \mathrm{U} \mathrm{mL}^{-1}$ of insulin was dissipated between 0 and $30 \mathrm{~min}$ before the maximum concentration was reached. Insulin level in the interstitial tissue in a remote compartment was also simulated and is shown in Fig. 4. It started from $0 \mathrm{~min}$ and steadily increased to $0.002 \mu \mathrm{UmL}^{-1}$ at $120 \mathrm{~min}$.

Statistical analysis was carried out shows group difference for quantitative variables, which were tested by Analysis of Variance (ANOVA) for plasma glucose and plasma insulin, respectively. There was no statistical difference $(\mathrm{p}<0.05)$ between the measured and simulated mean plasma insulin levels and the corresponding plasma glucose levels.

The data generated from the SITT were grouped into eight categories as follows: Male control subjects, Female control subjects, Male diabetic subjects, Female diabetic subjects, Control subjects of age $\leq 35$, Control subjects of age $>35$, Diabetic subjects of age $\leq 35$ and Diabetic subjects of age $>35$. Average values from each group were used in further analyses. Figure 5 shows the exit age distribution function. The average $k_{\text {measured }}$ value was calculated from each category and the results are presented in Table 1.

Table 2 shows the k-values derived from the model equations for the 8 categories. Each k, was determined from the slope of the line drawn by plotting natural log concentration values representing each group against time.

Comparison between measured rate constants and the simulated rate constants using Analysis of Variance
(ANOVA) was carried out using the in-built analysis tool pack from Microsoft Excel (2000) XP-professional.

\begin{tabular}{lc} 
Table 1: Average measured k values \\
\hline Group No. & ${\text { Average } \mathrm{k}_{\text {maasure }} \mathrm{Min}^{-1} \times 10^{-2}}^{2.783 \pm 0.98182}$ \\
\hline 1 & $3.625 \pm 0.76562$ \\
3 & $1.773 \pm 0.71804$ \\
4 & $1.871 \pm 0.94748$ \\
5 & $3.238 \pm 0.98484$ \\
6 & $3.029 \pm 0.98213$ \\
7 & $1.688 \pm 0.86790$ \\
8 & $1.832 \pm 0.80673$ \\
\hline
\end{tabular}

Values are presented as mean $\pm \mathrm{SD}$

Table 2: $\mathrm{k}$-values derived from mathematical model ( $\mathrm{k}$ simulated)

\begin{tabular}{lc}
\hline Group No. & Average $_{\text {simulated }} \operatorname{Min}^{-1} \times 10^{-2}$ \\
\hline 1 & 2.667 \\
2 & 3.875 \\
3 & 1.286 \\
4 & 1.100 \\
5 & 3.083 \\
6 & 2.818 \\
7 & 2.167 \\
8 & 1.800 \\
\hline
\end{tabular}

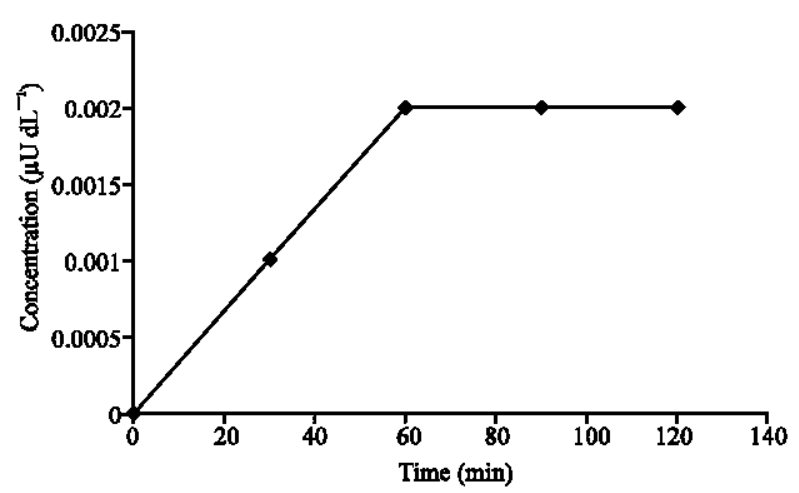

Fig. 4: Profile interstitial insulin

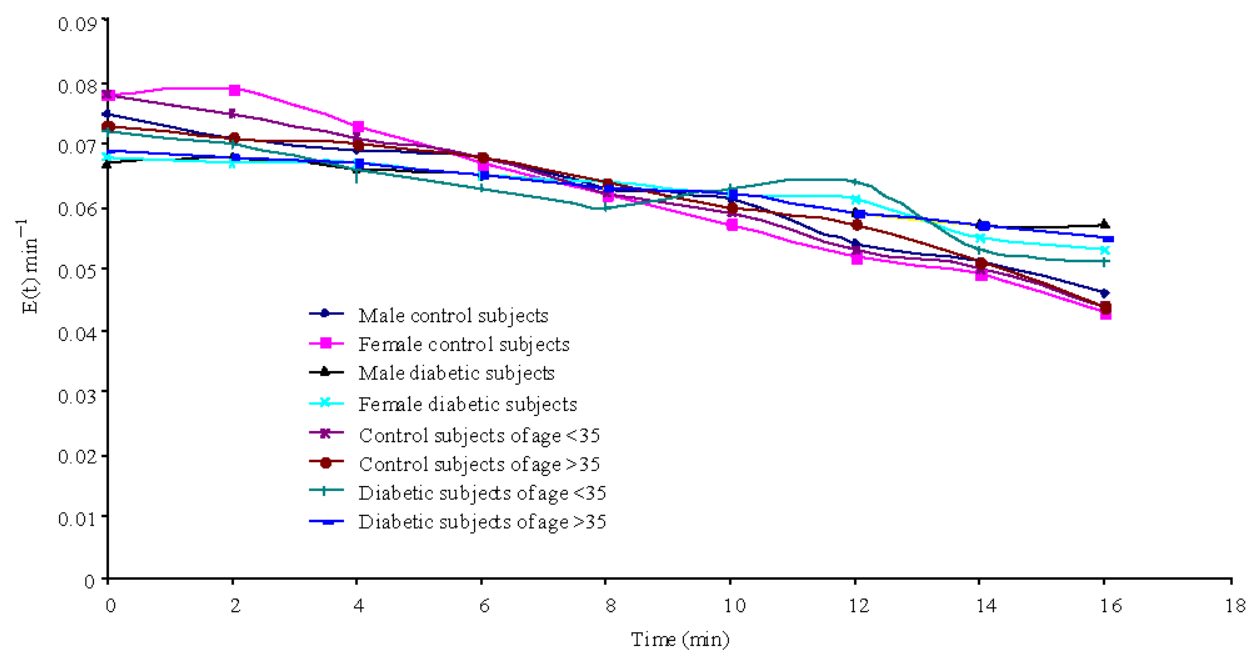

Fig. 5: Exit age distribution function 
Res. J. Applied Sci., 5 (1): 1-6, 2010

\begin{tabular}{|c|c|c|c|c|c|c|c|c|}
\hline Parameters & $\begin{array}{l}\text { Male } \\
\text { control } \\
\text { subjects }\end{array}$ & $\begin{array}{l}\text { Female } \\
\text { control } \\
\text { subjects }\end{array}$ & $\begin{array}{l}\text { Male } \\
\text { diabetic } \\
\text { subjects }\end{array}$ & $\begin{array}{l}\text { Female } \\
\text { diabetic } \\
\text { subjects }\end{array}$ & $\begin{array}{l}\text { Control } \\
\text { subjects } \\
\text { of age } \leq 35\end{array}$ & $\begin{array}{l}\text { Control } \\
\text { subjects } \\
\text { of age }>35\end{array}$ & $\begin{array}{l}\text { Diabetic } \\
\text { subjects } \\
\text { of age } \leq 35\end{array}$ & $\begin{array}{l}\text { Diabetic } \\
\text { subjects } \\
\text { of age }>35\end{array}$ \\
\hline Rate constant $\left(\mathrm{k} \min ^{-1}\right)$ & 0.02783 & 0.03625 & 0.01773 & 0.01871 & 0.03238 & 0.03029 & 0.01688 & 0.01832 \\
\hline Number of tanks (n) & 3 & 3 & 3 & 3 & 3 & 3 & 3 & 3 \\
\hline Residence time $(\tau(\min ))$ & 7.39 & 7.18 & 7.76 & 7.69 & 7.29 & 7.41 & 7.60 & 7.72 \\
\hline Conversion $(X)$ & $18.0 \%$ & $21.9 \%$ & $20.2 \%$ & $13.0 \%$ & $20.2 \%$ & $19.4 \%$ & $11.8 \%$ & $12.9 \%$ \\
\hline
\end{tabular}

Table 3 shows the summary of model parameters for the gut and blood compartments designed as three mixed flow tanks in series.

Lastly, the result obtained for rate constants using a model-based approach were similar to those derived from least squares estimation techniques by Fasanmade (1987). Using student t-test, there was no significant difference between the results obtained from both methods $\left(\mathrm{T}_{\text {cal }}>\mathrm{T}_{\text {table }}\right)$. Analysis of Variance (ANOVA) also revealed that there was no significant difference between the results $\left(\mathrm{F}<\mathrm{F}_{\text {crit }}\right)$.

A model of the gut and blood stream was developed by describing the body as a compartment/tank with a basal concentration of glucose and insulin by using mathematical equations. The gut-blood system is modeled as an infinite number of continuous stirred tanks in series, which could be used as simulators of the entire blood glucose-insulin system and the pathway for diabetes development.

The model makes it possible for the development of software that is used for therapeutic management of patients. The model gives some indicators and parameters that give idea of the level of development of the diabetes.

\section{CONCLUSION}

We have developed a new approach to model for the metabolism of glucose, its effectiveness and the sensitivity of insulin in individuals using infinite mixed reactors in series. It is capable of generating profiles of interstitial insulin, plasma glucose and insulin. The flow of glucose out of the blood compartment follows a first order kinetics as the solved model fitted the SITT data satisfactorily in all the plots. The exit age distribution and the mean residence times were determined. The results of the statistical analyses indicated that there was no significant difference between the model derived values of rate constants and the corresponding values calculated in the least square sense.

Software can be developed to simulate and estimate the Glucose-Insulin kinetic parameters. Furthermore, the software package can assist clinicians in early screening of patients at risk and treatment procedures for diabetic patients in any crisis situations.

\section{REFERENCES}

Bakari, A.G. and G.C. Onyemelukwe, 2005. Total Insulin output is low in type-2 diabetic Nigerians. Int. J. Diabetes Metab., 13: 93-95.

Bergman, R.N. and C. Cobelli, 1980. Minimal modelling, partition analysis and the estimation of insulin sensitivity. Fed. Proc., 39: 110-115.

Bergman, R.N., D.T. Finegood and S.E. Kahn, 2002. The evolution of beta-cell dysfunction and insulin resistance in type 2 diabetes. Eur. J. Clin. Invest., 32: $35-45$.

Bergman, R.N., R. Prager, A. Volund and J.M. Olesfsky, 1987. Equivalence insulin sensitivity derived by the minimal model method and euglycaemic glucose clamp. J. Clin. Invest., 79: 790-800.

Bonora, E., P. Moghetti, C. Zancanaro, M. Cigolini, M. Querena and V. Cacciatore, 1989. Estimates of Insulin action in man: Comparison of insulin tolerance test with euglycaemic and hyperglycaemic clamp studies. J. Clin. Endocrinol. Metab., 68: 374-378.

De Fronzo, R.A., J.D. Tobin and R. Andres, 1979. Glucose clamp technique: A method for quantifying secretion and resistance. Am. J. Physiol., 237: 214-223.

Fasanmade, O.A., 1987. A Study of Insulin Sensitivity in Selected Nigerian Subjects. CMUL, UK., pp: 4-41.

Gaetano, A.D. and O. Arino, 2000. Mathematical modeling of the intra-venous glucose tolerance test. J. Math. Biol., 40: 136-168.

Gerich, J.E., 1993. Control of glycaemia. Baillieres Clin. Endocrinol. Metab., 7: 551-586.

Himsworth, H., 1936. Diabetes mellitus: Its differentiation into insulin-sensitive and insensitive types. Lancet, 1: $127-130$.

Kahn, S.E., R.L. Prigeon, D.K. McCulloch, E.J. Boyko, R.N. Bergman and M.W. Schwartz, 1993. Quantification of the relationship between insulin sensitivity and beta cell function in human subjects. Diabetes, 42: 1663-1672. 
Makroglou, A., J. Li and Y. Kuang, 2006. Mathematical model and software tools for the glucose-insulin regulatory system and diabetes: An overview. Applied Numerical Math., 56: 559-573.

Seltzer, H.S., E.W. Allen, A.L. Herron and M.T. Brennan, 1967. Insulin secretion in response to glycaemic stimulus: Relation of delayed initial release to carbohydrate in-tolerance in mild diabetes. J. Clin. Invest., 46: 323-335.
Shen, S.W., G.M. Reaven and J.W. Farquhar, 1970. Comparison of impedance to insulin-mediated glucose uptake in normal subjects and in subjects with latent diabetes. J. Clin. Invest., 49: 2151-2160.

Topp, B., K. Promislow, G. de Vries, R.M. Miura and D.T. Finegood, 2000. A model of $\beta$-cell mass, insulin and glucose kinetics: Pathways to diabetes. J. Theoret. Biol., 206: 605-619. 